Este artigo apresenta o caso de Wu-Ying, um adolescente psicótico, através do qual tentamos analisar um dos possiveis caminhos que a elaboração psíquica pode seguir. A escolha de uma área transicional triangular, associando uma professora, uma psicopedagoga - ambas psicólogas - e uma obra literária, Plume, de Henri Michaux, permitiram a Wu-Ying subjetivar a sua história, graças ao jogo dinâmico de passividade e atividade.

Psicose; transicional; subjetivação

A ORDINARY FACT TALE ANALYTICAL - PSYCHO PEDAGOGY AND SUJB. JECIIVITY

Through the case of Wu-Ying, a psychotic teenager, we are trying to show what paths the psychic link work can borrow. The choice of a transitional area to three associating a French teacher and a psycho pedagogue - all two clinician psychologists and the company of an original literary work, Feather by Henri Michaux, have allowed Wu-Ying to subjective his history, thanks to the dynamic game of passivity and drive activity.

Psychosis; transitional; subjectivity

\section{UM CONTO DE FATOS COMUNS - PSICOPEDAGOGIA ANALÍTICA E SUBJETIVAÇÃO}

\author{
Teresa Rebelo \\ Isée Bernateau
}<smiles>c1ccccc1</smiles>

urante a sua primeira sessão de psicopedagogia analítica ${ }^{1}$, Wu-Ying, um adolescente psicótico de 17 anos, perguntou-nos: "Existe oxigênio suficiente no ar para respirar?" Esta pergunta levou-nos a entender para que tipo de sobrevivência ele esperava a nossa ajuda. Ele sentia uma constante sensação de sufoco, que um pesadelo repetitivo punha em cena: "Num mundo sem oxigênio, queimado pelo sol, eu estou perdido. Sufoco, estou sozinho e estou morrendo. Os meus pais e o meu irmão se refugiaram numa loja de plantas, onde existe ainda ar. Eu olho para eles através da vitrine, mas eles não me vêem e não consigo ir ter com eles". Dobrado sobre si mesmo na cadeira, ele colocava a cabeça entre suas mãos, como para adormecer ou para tentar fugir a qualquer eventual contato, demonstrando não entender tudo o que nós lhe dizíamos, de ter poucos pontos de apoio e de evoluir num mundo de terror e de angústia que lhe escapava completamente.

- Psicopedagoga e psicóloga do Hospital-Dia Cerep-
Montsouris, de Paris - França.

a - Professora de letras e psicóloga do Hospital-Dia Cerep-Montsouris, de Paris-França. 
Wu-Ying, de origem chinesa, chegou ao hospital-dia ${ }^{2}$ com 14 anos, depois de uma hospitalização de dez meses provocada por um "estado delirante alucinatório e uma fobia escolar". O quadro clínico descrito é o de uma "psicose infantil" ou de uma "desarmonia psicótica" não detectada durante a infância seguida de uma descompensação da adolescência. A sua história conta uma hospitalização quando ele tinha apenas três semanas por causa de uma "insuficiência respiratória aguda com risco de morte iminente". Quando o bebê volta à sua mãe, após três semanas de hospitalização, ele não tem o reflexo de sucção e não se alimenta mais. Ele tem que ser hospitalizado, uma vez mais, para ser alimentado através de uma sonda. Em seguida, as coisas parecem ter se passado sem incidentes maiores. Isso até a hospitalização aos 14 anos, o que vai acarretar uma interrupção brutal da escola. Ele ficará hospitalizado vários meses em psiquiatria infantil. Quatro anos de tratamento institucional já se passaram quando começamos a trabalhar com ele.

O tratamento do tipo psicopedagógico é proposto diante das dificuldades da professora de Letras perante este adolescente triste, sem um nível escolar concreto, cuja escolaridade consiste em decorar verbos e listas de palavras. Não sabendo por onde começar, a psicopedagoga inaugura um tipo de trabalho experimental. Este trabalho se organizará em torno da leitura de Plume, de Henri Michaux. Esta obra foi escolhida em razão dos seus capítulos curtos e da sua atmosfera estranha, ao mesmo tempo angustiante e cômica. Nesta antologia de poemas em prosa, publicada em 1930, Plume é o relato das aventuras surrealistas do herói, personagem simpático, passivo e pasmado. Personagem que passeia num mundo absurdo e com regras implacáveis e arbitrárias, submergido de uma culpabilidade radical e absoluta. A sua fraqueza é alvo da crueldade alheia e cada capítulo tem ares de um novo pesadelo que começa. Mas, como ele é "leve como uma pluma", ele atravessa sem grandes danos estas etapas extremamente dolorosas.

Durante as primeiras sessões, Wu-Ying parece cansado, apático. Ele se deita sobre a mesa, parecendo bastante confuso. Mas, desde o primeiro capítulo, ele parece ter empatia com Plume, com o qual ele se identifica, sentindo não tanto a sua fragilidade, mas a sua força. $O$ universo "d'inquiétante étrangete" ${ }^{4}$ no qual Plume vive parece-lhe ser estranhamente familiar. Pedimos então a Wu-Ying para escrever uma continuação de cada um dos pequenos capítulos da antologia. Ele começa então um movimento que o faz tirar Plume das situações complicadas em que Michaux escolhera para o deixar. Suas continuações serão tentativas de atribuir sentido a um universo confuso e de nonsense perpétuo. Através da sua identificação com o herói, ele parece começar um trabalho de restauração narcísica. 
As dificuldades de Plume, ao mesmo tempo em que o confrontam à sua própria fragilidade, vão lhe permitir "vencer" a passividade através da sua nova atividade de escritor. Esta reviravolta da passividade para atividade aparece para Wu-Ying como uma constituinte de um começo de subjetivação, num duplo registro: por um lado, ele é aquele que decide o destino de Plume; por outro lado, Plume, esse ser passivo e em constante dificuldade, através da pluma ${ }^{5}$ de WuYing é um herói, sujeito da sua própria história. A obra literária, neste caso, é uma área transicional, um espaço em que as quimeras tornam-se realidades imagináveis. A obra propõe um espaço de fantasia que Wu-Ying pode tornar seu e apoiar-se nele para a reorganização de seu próprio espaço psíquico: "Para o adolescente o encontro com o objeto artístico, objeto encontrado e criado do escritor ou do pintor, funciona [então] como uma antecipação do sucesso da obra que ele mesmo tem a realizar, a sua própria realização" (Richaud, 2000, p. $67)^{6}$. Com efeito, Plume tem a função de espelho duma psique que não possui ainda uma capacidade de auto-reflexão, e como um medium maleável, base de transformações em que WuYing pode se sentir protegido.

Mas, se Wu-Ying pode assim "brincar" com Plume, isso não é só devido ao seu encontro com uma obra de arte em um tratamento do tipo psicopedagógico. Ao mesmo tempo, um trabalho semelhante com a psicopedagoga transforma-se em leituras monótonas e em um trabalho de escritura mecânica. A dinâmica do nosso trabalho deve-se não somente ao medium maleável constituído pela obra de arte, mas também à triangulação das relações. Triangulação que coloca o jogo no centro das inter-relações. Ora, a triangulação que permite esse jogo, propondo alianças que se fazem e se desfazem sem cessar, obriga os três participantes a serem tanto passivos quanto ativos, sem que haja uma fixação numa ou noutra posição. Assim, numa dinâmica próxima do psicodrama, a psicopedagoga e Wu-Ying, por exemplo, opõem-se à professora - o que permitirá um trabalho de desdramatização do escolar e das angústias relacionadas -, ou então Wu-Ying e a professora rejeitam a psicopedagoga, por causa da sua "incompetência", e assim as alianças sucedem-se. Esses conflitos relacionais irão libidinalizar as sessões e Wu-ying poderá expressar, através do jogo transferencial, um sadismo que, até então, não tinha encontrado um ponto de fuga. Nesse sentido, a capacidade de Wu-Ying de se mostrar ativo parece demonstrar essa "desalienação com relação ao poder, ao prazer do outro"7 que R. Cahn (1999, p. 36) considera como constitutivo do processo de subjetivação. Não se deixar levar é, para Wu-Ying, um ato que constitui a diferença ao outro e que the permite colocar-se como sujeito criador, escritor em igualdade com Michaux, capaz de exercer um poder sobre a sua criação.

No entanto, o capítulo XI de Plume, "O Convidado de Honra do Bren Club", coloca Wu-ying em uma situação difícil. Depois da leitura, ele se mostra incapaz de escrever "a sua continuação do texto". Decidimos, então, escrevê-la juntos, "uma 
frase cada um". Propomos a transcrição integral deste capítulo, assim como a continuação "a três vozes", pois o conteúdo demonstra a imbricação da riqueza da fantasia do texto e da dimensão transferencial da relação que faz do encontro com a obra literária uma atividade propícia à subjetivação.

\section{O CONVIDADO DE HONRA DO BREN CLUB ${ }^{9}$}

O convidado de honra comia lentamente, metodicamente, não fazendo nenhum comentário.

O peru estava recheado de vermes, a salada tinha sido lavada com óleo, as batatas tinham sido cuspidas. O pé de laranjeira deve ter crescido em terra de naftalina, os champignons tinham sabor de aço, o patê cheirava a sovaco, o vinho era vinho como o bicarbonato.

Plume, sem levantar a cabeça, comia pacientemente. Uma serpente caiu do cacho de bananas e foi em sua direção; ele a engoliu por educação, voltando a se concentrar no seu prato.

Para chamar a sua atenção, a dona da casa mostrou-lhe um dos seus seios. Desviando o ollar ela ria sem graça.

Plume, sem levantar a cabeça, comia.

"Você sabe como se alimenta uma criança?", ela the perguntou, agitando-se repentinamente, e ela o cheira. Por uma questão de honestidade, ele a cheira também, delicadamente. Pouco depois, chorando, a sua vizi- nha da esquerda se engasga, com uma lingua de carneiro que, estupidamente, ela tinha decidido engolir. Deram-lhe os tratamentos adequados. Disfarçadamente, um segurava-lhe as narinas praticamente obstruídas, outros, com a desculpa de ajudála, apertavan-lhe o pescoço. E nunca mais ela cedeu-lhes a língua a qual ela queria tanto renunciar.

Assim, a vida, sempre pronta a escapulir, deixou-a silenciosamente.

"Não leve a mal", disse Plume à dona da casa, com os olhos brilhantes e arregalados. "Ao engolir as línguas, tem sempre alguém que falha. Poderia ter sido você. Poderia ter sido eu. Felicitemo-nos. Vamos nos divertir. Gostaria que as crianças assistissem a este momento. Elas gostam tanto da felicidade."

E ela batia nele beijando-o.

Henri Michaux, Plume.

Segue a "continuação" criada pelos três participantes:

- Teresa Rebelo: Ele olhou seus companheiros e disse: "Obrigado meus amigos, com uma cara satisfeita." Ele mente. Na realidade, ele os odeia e ele está furioso com estas férias no Bren Club.

- Isée Bernateau: Porque neste clube horrivel ele foi humilhado, explorado, ridicularizado. E ele, Plume, só tinha vontade de gritar:

- Wu-Ying: "Socorro", Plume só pode gritar "socorro" para salvar a sua vida. O Bren Club leva-o para a sala e dá-lhe uma comida de cão.

- Isée Bernateau: Plume não quer mais ser tratado desta maneira. Ele decide se rebelar.

- Wu-Ying: Ele pega nas pinças de lagosta podre e os belisca na bunda, que fica vermelha como um tomate. 
- Teresa Rebelo: Plume ri, ele não para de rir. É superengraçado.

- Isée Bernateau: Mas Plume também é uma pessoa legal. Ele procura pela sua namorada: onde é que ela poderia estar? Plume liga para a polícia. Ele diz:

- Wu-Ying: "Senhor policial, por favor, poderia me ajudar a encontrar a minha namorada, Esmeralda? Já estou ficando desesperado."

- Teresa Rebelo: Bem. De repente, toca o telefone. É Esmeralda: "Plume, meu amor, há duas horas estou esperando por você no restaurante."

- Wu-Ying: "Esmeralda, você quer comer pinças de lagosta podre?"

- Isée Bernateau: "Me responda Plume, onde você estava?"

- Wu-Ying: "Estava preso no Bren Club. Eles me obrigaram a ficar."

- Teresa Rebelo: "Sim, mas eu estou esperando por você, venha já!"

- Wu-Ying: "Estou indo querida!"

- Isée Bernateau: E Plume desliga e sai correndo, seguido por seus inimigos do Bren Club.

Em 'Construction dans l' analyse" ${ }^{10}$, Freud salienta que o trabalho que $o$ analisante faz na cura não deve fazer com que seja esquecido o trabalho do analista, que deve "construir o que foi esquecido" "1937, pp. 270-271). $\mathrm{Na}$ seqüência que transcrevemos, uma construção deste tipo foi feita. Ela evidencia a complexa imbricação pulsional em torno do tema da oralidade, central para Wu-Ying. O "Bren Club" será a ocasião para Michaux evocar a oralidade que mata em vez de alimentar, que dá a morte em vez da vida.

B. Penot (2001), referindo-se a uma paciente bulímica, faz a ligação entre o destino mortífero da libido oral e de um defeito qualitativo da "passivação" nas relações precoces mãe-filha:

"Toda procura de satisfação afetiva em um modo passivo pareceria, com efeito, não poder senão precipitá-la em uma dependência incondicional, degradante. Isto fazia supor (no sentido das construções na análise) que uma forte necessidade de domínio vivido por sua mãe (o horror que ela tinha da passivação) havia podido conferir à troca pulsional entre elas. No início, um caráter mortífero, hipotecando a evolução de sua libido oral." เ2

Assim, se a passivação, procura ativa de um objetivo passivo, não pode se tornar um modo de satisfação pulsional, ela se transforma em pura submissão. A luta contra essa alienação é parecida com a oralidade mortífera que o texto de Michaux coloca em cena. A partir daquilo que Wu-Ying pode verbalizar, poderíamos dizer que uma vivência subjetiva de uma carência de experiências de subjetivação entre ele e a mãe pode ser a origem de uma angústia vivida como mortífera. Nosso dispositivo possibilita uma experiência subjetivizante de passivação: Wu-Ying encontra prazer em "ser olhado", sem viver isto como uma experiência de alienação insuportável. Neste espaço de jogo, ele recebe algo de um outro reconhecido como sujeito.

Plume vem acompanhar uma vivência de Wu-Ying, o jogo se transforma em realidade, o transicional faz o elo entre a representação e os afetos. Escrevendo a continuação do capítulo XI de Plume, como um squiggle, nós tecemos, a três, um texto 
que permitirá a expressão de uma vivência subjetiva até então impensável e, por conseqüência, inefável. À representação de coisa sucede uma representação de palavra. Tendo que enfrentar uma angústia arcaica, o "Plume" de Wu-Ying só pode gritar "socorro" para salvar a sua vida. Este grito de "hiflosigkeit", sem esperança de socorro, Wu-Ying pode pronunciá-lo pela voz de Plume, mesmo se Plume não tem forças para enfrentar o Bren Club que "leva-o para a sala e dá-lhe uma comida de cão”. A professora retorna à passividade do Plume de Wu-Ying em atividade: "Ele decide se rebelar". Mas Wu-Ying, neste jogo parecido com um psicodrama, torna-se um participante ativo desta dinâmica de transformação. $O$ que o faz evoluir de uma passividade vivida como alienante e degradante a uma atividade pulsional libidinalizada: "Ele pega nas pinças de lagosta podre e os belisca na bunda, que fica vermelha como um tomate". No seu enunciado, o substantivo "pinças" transforma-se em verbo ativo, agente de uma ação que torna possivel o trabalho do objeto oral vivido como mau - "as pinças de lagosta podre" - transformando-se em bom objeto, oral e erotizado: "a bunda fica vermelha como um tomate".

Nesta transformação, a expressão da agressividade - "de os belisca na bunda" - tem um papel fundamental. Assim, reconhecendo o estado de desespero, Wu-Ying parece poder ter acesso à possibilidade de atacar o objeto, sem que este ataque ameace a sua integridade. Após sublinhar a ambivalência de Plume - "Mas Plume também é uma pessoa legal" - a professora integra uma "namorada". Esta "na- morada" não poderá ser considerada como o sinal do acesso de Wu-Ying à genitalidade. No entanto, o fato de que ele se aproprie deste novo dado, dando-lhe o nome de Esmeralda e convidando-a para "comer pinças de lagosta podre”, isto é o testemunho da sua capacidade de utilizar a dinâmica do squiggle ${ }^{13}$ para colocar em cena uma oralidade arcaica e sádica através de uma relação amorosa.

Depois que terminamos a leitura de Plume, Wu-Ying aproveita a flexibilidade dos papéis de cada um para propor que escrevamos juntos a continuação das aventuras de Plume. Ele decide que o primeiro capítulo será intitulado "Plume no enterro" e começa o texto: "Era uma vez, no dia 31 de março de 1982, dia do enterro de Nádia, o bebê de Plume. Durante a noite, Plume e sua mulher choram juntos". Wu-Ying parece poder subjetivar e humanizar algo da agonia e do desespero vividos até então. Assim, a notícia da morte é acompanhada de um sentimento de tristeza e de uma emoção intensa que dará ao texto uma tonalidade de luto e de separação possíveis de se expressar sem que haja um desmoronamento melancólico. Wu-Ying terminará assim o seu texto: "Pluma coloca as flores, compradas num supermercado. 'Adeus Nádia, não te esquecerei nunca'. E Plume volta para casa." Pensar o nascimento como uma morte é acompanhado, no seu texto, da aceitação do elo da lembrança que perdura além da perda da criança, elo cujas flores são o símbolo de vida. Assim, a déliasion ${ }^{14}$ e o nonsense serão substituídos por palavras que darão a esta experiência, impensável senão, forma e sentido. 
Após a separação das férias de verão, pedimos a Wu-Ying para nos contar, por escrito, um episódio de suas férias. Plume, a partir de então, constitui um "espaço transicional" suficiente para que seja possível deixá-lo um pouco de lado. Wu-Ying escreverá cartas que contarão o seu aniversário, um jogo de pingue-pongue, um programa de televisão e, aos poucos, ele começa a descrever a vida dos seus pais na China. Ele evoca a vida dificil, a falta do mínimo para a sobrevivência e termina assim a sua história: "O meu pai e a minha mãe achavam muito dificil a vida que tinham, com apenas um pouco de arroz diário. Eles pediram para ir para a França, receberam a autorização e vieram em 1974". Soubemos depois que para poder escrever este texto, ele fez um verdadeiro "inquérito" e questionou bastante os seus pais.

A partir de então, Wu-Ying, que fala cada vez mais de sua família, questiona-se sobre a sua maneira de viver, as suas crenças, os seus hábitos, pedenos para criar uma ficção. Inspirandose em um programa da televisão, ele escreve "A história triste de uma criança na Índia", uma criança vendida pelos seus pais a um fabricante de tapetes que o explora e bate nele. Wu-Ying evocará também a sua bondosa avó que quer the dar dinheiro, que ele recusa "porque ela é pobre". O próximo texto, "A criança africana que não tinha nada", é a história de Idrissa, que deixa a sua malvada mãe para ir morar com a avó. Um dos capítulos - "O momento trágico de Idrissa" - conta a morte da avó, atropelada por um carro enquanto Idrissa "tem uma vontade imperiosa". No último capítulo, Idrissa reencontra os seus verdadeiros pais, que o procuravam havia anos. Por fim, Wu-Ying começa um "romance policial" de uma família perfeita e feliz, em que se pode ler num dos capítulos: "Enquanto Mickaël e Christian vão embora, os pais relaxam". $\mathrm{Na}$ semana seguinte, Wu-Ying lê para nós a primeira frase do capítulo: "Voltando ao fim do dia, as crianças abrem a porta devagarzinho para não acordar os pais". A cena primitiva aconteceu "fora da vista", num tempo de latência que une, de maneira invisível, mas segura, uma sessão à outra.

O elo que se tece provém igualmente das diferentes "construções" que realizamos a partir do material que ele produz. Fazendo ligações com o que sabemos da sua história e com o que ele nos diz. É a construção progressiva desta "história" de Wu-Ying, "história" da qual mostramos alguns instantes, mas sabemos também ser em parte mítica, o que entretanto tornou possível o nosso trabalho com ele. Uma das características desta "história" é a sua plasticidade: ela é incessantemente transformada, aumentada, amenizada, às vezes em contradição com aquilo que Wu-Ying escreve. Este eterno movimento de ajuste parece também estar incluído na dinâmica do retorno dialético dos modos de satisfação pulsional e de troca. De tal maneira que esta dinâmica se transforma no testemunho de nosso consentimento, posicionando-nos de maneira sucessiva e alternada em posição ativa e passiva, num jogo que torna viável o começo de uma dinâmica de subjetivação.

Hoje, Wu-Ying elabora diferentes "cenários" de uma história subjetiva em constante mutação. Ele realiza, 
através da sua pluma, os seus sonhos, expressa as suas dúvidas, as suas fantasias, os seus conflitos. Ele enriquece a sua vida fantasmática, enriquecendo-a ao mesmo tempo em que se apodera dela. A sublimação retoma os seus direitos de modo de satisfação pulsional. Esta aventura subjetiva foi possível graças à liberdade que nos é dada para trabalhar e pela qualidade dos laços que nos unem. Laços que permitiram suportar a déliaison psicótica e aceitar os momentos dificeis, quando a luz no fím do túnel não era perceptivel. E, como nos pede Wu-Ying antes das férias: "A gente poderia falar outra vez de Plume?".

\section{REFERÊNCIAS BIBLIOGRÁFICAS}

Cahn, R. (1999). Pertinence de l'œuvre d'A. Green pour une théorisation de l'adolescence. In Adolescence, 17, 1, pp. 9-100.

Freud, S. (1915). Pulsions et destins des pulsions. In Métapsychologie. Paris: Gallimard, 1968.

(1919). L'inquiétante étrangeté et autres essais. Paris: Gallimard, 1985.

(1937). Constructions dans l'analyse. In Résultats, idées, problèmes, II. Paris: PUF, 1985.

Green, A. (1980). Passions et destins des passions. In La Folie privée. Paris: Gallimard, 1990.

Gutton, P. (1991). Le Pubertaire. Paris: PUF. Michaux, H. (1930). Plume, précédé de Lointain intérieur. Paris: Gallimard, 1963.

Penot, B. (2001). La passion du sujet freudien. Entre pulsionnalité et signifiance. Paris: Erès.

Richaud, R-L. (2000). Une maieutique du sujet pensant. Paris: L'Harmattan.

Winnicott, D. W. (1971). Jeu et Réalité, Paris: Gallimard, 1975.

\section{NOTAS}

1 Psicopedagogia analitica com dois terapeutas: Teresa Rebelo - psicopedagoga e psicóloga - e Isée Bernateau - professora de letras e psicóloga.

2 Hospital-Dia para adolescentes do CerepMontsouris, 20, Bd Jourdan, 75014, Paris. O Cerep-Montsouris é uma instituição que recebe adolescentes com grande dificuldade psíquica, tendo uma equipe multidisciplinar (técnicos de saúde e professores).

3 Termos que estão mencionados no seu prontuário médico no momento de sua admissão.

4 "Inquiétante étrangeté" é a tradução para o francês do termo freudiano "unheimlich", que em português se traduz como "estranho familiar". (N.E.)

5 "Pluma” em francês significa "pena". A traduçã correta da expressão seria "na pena (de escrever) de Wu-Ying"; para manter o jogo de palavras Plume (nome do personagem) e Pluma (pena de escrever). (N.E.)

6 R-L Richaud. (2000), tradução das autoras.

7 R. Cahn. (1999), tradução das autoras.

8 Tradução das autoras.

9 Tradução das autoras.

10 S. Freud, Construction dans l'analyse (1937, in Résultats, idées, problèmes, Paris, PUF, 1985, pp. 270-271 (trad. das autoras).

11 Tradução das autoras.

12 Desamparar. (N.E.)

13 "Squiggle" significa "rabisco" e é uma referencia ao "jogo do rabisco", de Winnicott. (N.E.)

14 Desconexão. (N.E.)

Recebido em fevereiro/2002. 